\title{
Management options for food production systems contaminated as a result of a nuclear accident
}

\author{
A. Nisbet \\ National Radiological Protection Board, Environmental Assessments Department, \\ Chitton OX11 ORQ, U.K
}

\begin{abstract}
In the event of a nuclear accident, the imposition of mandatory intervention levels for foodstuffs could result in substantial quantities of agricuthural produce being considered unfit for human consumption. Milk is important in this respect due to the continuous nature of its production and the rapid transfer of radionuclides from pasture to milk. A five-year research project funded jointly by Food Standards Agency. Environment Agency and NRPB, has been carried out to evaluate comprehensively, options for the management of contaminated foodstuffs following a nuclear accident. This has identified three broad strategies for handling milk, cereals, fruit and vegctables: in situ treatments, altemative uses and disposal. For milk there is also the possibility of rapidly reducing the production of waste milk. The practicability of these options was evaluated against a set of 6 criteria: technical feasibility, capacity, cost, environmental impact, radiological impact and acceptability. These were assessed quantitatively where possible through consultation with experts from a wide range of organisations. Detailed radiological impact assessments were also undertaken. The radionuclides of interest were ${ }^{131} 1,{ }^{134,137} \mathrm{Cs}$ and ${ }^{89,90} \mathrm{Sr}$. This paper provides an overview of the assessment of practicability and makes recommendations on the most appropriate options according to the type of agricultural produce affected.
\end{abstract}

\section{INTRODUCTION}

Regulations from the Council of the European Communities specify intervention levels (CFILs) for radionuclide concentrations in marketed foodstuffs that would be legally binding on the UK in the event of a future nuclear accident or other radiological emergency [1]. Depending on the scale and timing of an accidental release of radionuclides, large quantities of agricultural produce may become contaminated above these levels and would be banned from directly entering the foodchain. Milk is of particular concern in this respect due to the continuous nature of its production and the rapid transfer of radionuclides from pasture to milk. The potential scale of the probiem can be illustrated by the Windscale accident in 1957: if current CFILs for I-131 had been in place, then about 86 million litres of milk would have required disposal over a period of about 6 weeks. UK licensed nuclear sites are required to have emergency plans, but these do not generally deal with the practicalities of handling large quantities of waste foods such as milk or cereal crops. As part of contingency planning it is important therefore to identify practicable options for managing restricted produce. This paper brings together work carried out in this area over the last five years. It provides an overview of the options and an assessment of their practicability.

\section{OPTIONS}

Options for the management of contaminated foodstuffs may be divided into three broad strategies involving in situ treatment, alternative use and disposal. For milk there is also the possibility for rapidly reducing the production of waste milk. The full range of options considered and their appropriateness for different types of foodstuffs is presented in Table 1. A full description of these options has been given elsewhere [2-9]. 
Table 1 Management options for food production systems contaminated as a result of a nuclear accident

\begin{tabular}{|c|c|c|c|c|}
\hline & Options & \multicolumn{2}{|c|}{ Crops } & Milk \\
\hline & & Arable & $\begin{array}{c}\text { Vegetables and } \\
\text { Fruit }\end{array}$ & \\
\hline In situ treatments & $\begin{array}{l}\text { Ploughing in after desiccation } \\
\text { Landspreading on the farm } \\
\text { Burning } \\
\text { Composting }\end{array}$ & & $\underset{7}{7 / a}$ & $\begin{array}{c}\mathrm{n} / \mathrm{a} \\
\mathbf{n} \\
\mathrm{n} / \mathrm{a} \\
\mathrm{n} / \mathrm{a}\end{array}$ \\
\hline Altemative use & $\begin{array}{l}\text { Processing/decontamination/storage } \\
\text { Animal feeding } \\
\text { Commercial composting }\end{array}$ & & $\frac{7}{2}$ & $\begin{array}{l}7 \\
7 \\
n / a\end{array}$ \\
\hline Disposal & $\begin{array}{l}\text { Landfill } \\
\text { Biological treatment (aerobic/anaerobic digestion) at } \\
\text { sewage treatment works (STW) or dairy plants } \\
\text { Sea via coolant water outfalls at nuclear sites or long } \\
\text { sea outfalls at STW } \\
\text { Incineration }\end{array}$ & $n / a$ & 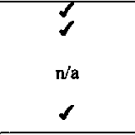 & $\begin{array}{l}\mathbf{n} / 8 \\
7 \\
\mathbf{n} / 8\end{array}$ \\
\hline $\begin{array}{l}\text { Minimise } \\
\text { production of } \\
\text { contaminated milk }\end{array}$ & $\begin{array}{l}\text { Reduce pasture intake } \\
\text { Dietary additives to suppress uptake } \\
\text { Suppress lactation by administering hormones or } \\
\text { through drying-off naturally } \\
\text { Slaughter }\end{array}$ & $\begin{array}{l}n / a \\
n / a \\
n / a\end{array}$ & $\begin{array}{l}\mathbf{n} / \mathbf{a} \\
\mathbf{n} / \mathbf{a} \\
\mathbf{n} / \mathbf{a} \\
\mathbf{n} / \mathbf{a}\end{array}$ & $\frac{7}{7}$ \\
\hline
\end{tabular}

may also be considered as disposal options.

2 not applicable.

\section{APPROACH}

In order to implement any of the options listed above, they must be practicable for use under the conditions prevailing at the time of the accident. These will vary on a site by site basis and depend on the scale of the accident. Practicability comprises six main factors that need to be considered before the optimum strategy for managing contaminated foodstuffs can be selected [2]. These are technical feasibility, capacity, cost, environmental impact, radiological impact and acceptability. A management option is considered to be technically feasible if the resources required to implement it are readily available. Capacity dictates the extent to which an option can be utilised (e.g. $1 \mathrm{~d}^{-1}, \mathrm{t} \mathrm{d}^{-1}$ ). Costs include estimates of both direct and hidden costs. Options may have some environmental impact through for example the generation of secondary wastes or by increasing the level of pollutants such as nitrates. Implementation of management options for contaminated foodstuffs will have a radiological impact on operatives ${ }^{1}$, farmers and members of the public. This is dependent on the radionuclide composition of the deposit, personnel involved in implementing the option and the pathways of exposure. Ultimately, an option must be acceptable to all stakeholders.

Information about these criteria was obtained from literature sources and consultations with agricultural specialists, industrial contacts and members of the UK stakeholder group on Agriculture and Food Countermeasures. In addition, where relevant, full radiological impact assessments were carried out based on scenarios where it was assumed that crops were contaminated at the CFIL with ${ }^{134} \mathrm{Cs},{ }^{137} \mathrm{Cs},{ }^{89} \mathrm{Sr}$ or ${ }^{90} \mathrm{Sr}$. For milk it was assumed that restrictions were in place for periods up to 3 months and that activity concentrations in milk at the end of these periods were equal to the relevant CFIL. The doses estimated did not take into account exposure to activity already present in the environment as a result of deposition: they represent only the incremental doses received as a result of implementing each management option. The radiological impact of an option was categorised as low $(<10 \mu \mathrm{Sv})$, medium $(10-300 \mu \mathrm{Sv})$ or high $(>300 \mu \mathrm{Sv})$. An individual dose of $10 \mu \mathrm{Sv} \mathrm{y}^{-1}$ is considered trivial for regulatory purposes [10], whilst $300 \mu \mathrm{Sv} \mathrm{y}^{-1}$ corresponds to the maximum dose constraint for controlled sources recommended for use in the UK [11]. Limiting concentrations of each radionuclide have also been calculated to give an idea of the range of options that would be available at different levels of deposition. These have been based on a dose criterion of $10 \mu \mathrm{Sv} \mathrm{y}^{-1}$.

\footnotetext{
' Individusls working at waste management facilities.
} 


\section{EVALUATION AND DISCUSSION \\ 4.1 Practicability of options for crops 4.1.ITechnical feasibility}

Most of the options listed are based on existing practices for managing organic wastes and are therefore technically feasible. However, crops would need to be chopped before landspreading or undergoing anaerobic digestion. The availability of these facilities could undermine the technical feasibility of these options. Burning is only feasible for dry biomass with low moisture content e.g. mature cereals.

\subsubsection{Capacity}

In situ treatments have high capacities enabling most of the above ground biomass to be managed on the farm. The capacity of other options such as commercial composting, food processing, incineration and biological treatment are determined by regional availability of commercial facilities: the spare capacity of which can be highly seasonal. The feeding of crops grown for human consumption to animals would probably be restricted to mixed farming systems at times of the year when meat-producing livestock are housed. The capacity of this option is further limited by the low inclusion rates of some crops in order to maintain nutritionally balanced and palatable diets. The capacity of the remaining option, landfill, is potentially high, if all the sites currently licensed to accept household waste could be used. If authorisation was only given for disposal to fully engineered sites, overall capacity would be reduced.

\subsubsection{Costs}

Options carried out in situ or on the farm are the least expensive because they avoid costs associated with the transportation of large volumes of biomass and charges levied by commercial operators. An earlier study [2] found there to be an order of magnitude difference in cost between in situ treatments and incineration, which is the most expensive option of all.

\subsubsection{Environmental impact}

The option with the greatest environmental impact is the burning of mature cereals. Large quantities of smoke and particulates are released during burning, affecting local communities and roads. Decomposition of foodstuffs at landfills may also have a negative environmental impact due to generation of odours, leachates and gas. Other options such as ploughing in, landspreading and the application of compost or dewatered cake from sewage treatment works (STW) to soil may in contrast have a beneficial effect by supplying organic matter and nutrients to the soil. Potential adverse effects such as run-off or leaching of nitrates can be avoided if government guidelines are followed.

\subsubsection{Radiological impact}

Doses from ${ }^{134} \mathrm{Cs}$ were estimated to be in excess of the dose constraint for operatives at STW handling crops contaminated at the CFIL. Doses from this radionuclide were also a substantial fraction of the dose constraint for operatives at landfill sites and commercial composting facilities. In each case external exposure was the dominant pathway. If composting is carried out by a farmer on a more opportunistic basis, relatively little time would be spent maintaining the heap. External doses would then be reduced [3]. Doses to farmers and members of the public from the other management options were all less than $10 \mu \mathrm{Sv}^{-1}$. When options were considered in terms of their limiting concentrations, ploughing in was found to be suitable for produce with activity concentrations of radiocaesium as high as $810^{4} \mathrm{~Bq} \mathrm{~kg}^{-1}$ ${ }^{134} \mathrm{Cs}$ and $210^{5} \mathrm{~Bq} \mathrm{~kg}{ }^{-1}{ }^{137} \mathrm{Cs}$. Limiting concentrations of ${ }^{96} \mathrm{Sr}$ as high as $310^{5} \mathrm{~Bq} \mathrm{~kg}^{-1}$ could be handled by incineration. The importance of the ingestion pathway for radiostrontium results in lower limiting concentrations for those options involving incorporation of contaminated foodstuffs on arable land. 


\subsubsection{Acceptability}

Any option that is perceived to undermine consumer confidence is likely to be unacceptable to stakeholders, whatever its strengths scientifically. Animal feed has now come under scrutiny following a number of high profile incidents involving genetically modified crops, BSE, dioxins and foot and mouth disease. Consequently, the feeding of contaminated cereals to animals would be difficult to justify to consumers and would therefore be unacceptable [5]. Similarly, the processing of foodstuffs to remove radionuclides or their dilution with clean material was also deemed to be generally unacceptable [6]. The option that received most support from stakeholders from food, retail and farming industries was the ploughing in of contaminated crops.

\subsection{Practicability of options for milk}

\subsection{Technical feasibility}

Whilst many of the options listed in Table 1 are based on existing practices and are therefore technically feasible, a few are not. For example, decontamination techniques such as ' $M A G * \mathrm{SEP}^{\mathrm{SM}}$, do not operate commercially in the UK and would require several weeks to set up following an accident. The feasibility of discharging milk to sea via coolant water outfalls may be undermined if it first has to be released into surge chambers surrounded by walls several metres high. Similarly, reducing the intake of contaminated pasture by dairy cows is not technically feasible if the housing, machinery and manpower necessary for the feeding of alternative diets are unavailable. Lactation can be suppressed by the administration of synthetic oestrogens, but these are currently banned for food producing animals in the European Union. Similarly, the licence for Prussian blue, the most effective dietary additive for reducing gut uptake of radiocaesium, expires in October 2001, making its future uncertain.

\subsubsection{Capacity}

Most options have some aspects that limit their capacity. The time of the year at which an accident happens markedly affects the capacity of farms to store waste milk and the availability of suitable land on which to spread it. Similarly, the availability of alternative feeds to substitute for pasture is limited for accidents occurring in April and May. The feeding of contaminated milk to other animals has very low capacity as it can only be incorporated into the diet of pigs. The volumes of milk that can be treated at STW and dairy effluent plants are limited by the very high chemical oxygen demand (COD) of milk, which can seriously affect process performance of biological treatments. In addition, spare capacity at these commercial facilities is typically $10 \%$ or less.

\subsubsection{Costs}

Costs of the options range considerably depending on whether they are carried out in situ or involve transportation. In all cases, compensation would be payable to farmers whose milk could not enter the foodchain through its normal route. Also, in situations where equipment is contaminated costs for decontamination would be incurred. Landspreading of milk in situ using existing equipment and personnel is one of the least expensive options. Disposal to sea through long sea, or coolant water outfalls is more costly because of long distance transportation and the additional manpower required. The most expensive option is that involving the slaughtering of dairy herds and subsequent disposal of carcasses. Additional compensation would be payable to farmers for replacement stock.

\subsubsection{Environmental impact}

The high biological oxygen demand (BOD), and nitrogen content of milk makes milk very poliuting if allowed to enter watercourses undiluted. The environmental impact of landspreading can be minimised if current legislation and guidance for the spreading of animal slurries is followed. Similarly, the disposal of 
milk to coastal water bodies also requires careful management to ensure that high dilution $\left(\sim 1\right.$ in $\left.10^{\circ}\right)$ is achieved. A recent study [7] has shown that these levels of dilution are achievable both at coastal STW and nuclear sites. Site-specific dispersion models for each long sea outfall in the UK can determine volumes of milk that could be discharged on a site-by-site basis without harming the environment.

\subsubsection{Radiological impact}

Options for minimising the production of contaminated milk would be expected to have minimal radiological impact because they either stop milk production completely or produce milk with activity concentrations less than the CFIL. However, where options involve the processing or disposal of large volumes of waste milk, the resultant doses to operatives, farmers and members of the public have to be considered using some cautious hypothetical scenarios. The radiological impact assessment carried out for landspreading indicated that doses to farmers and members of the public from all radionuclides were less than $10 \mu \mathrm{Sv}^{-1}[8]$. Doses to tanker drivers transporting milk from farms to long sea outfalls were also around or below $10 \mu \mathrm{Sv}$, whilst those to the public resulting from discharges of waste milk (containing around $10^{10} \mathrm{~Bq}$ of each radionuclide) into the sea were even lower than this [7]. In contrast, the biological treatment of milk either at STW or dairies could be limited by the doses to members of the public from consumption of river water and fresh water fish [9]. Subsequent treatment and disposal of sludge from STW or dairies by all routes other than incineration result in doses of less than $10 \mu \mathrm{Sv} \mathrm{y}^{-1}$.

\subsubsection{Acceplability}

A recent front-page headline in the national press [12] entitled "cancer fear over milk" appeared because of there being a possibility that milk might contain higher than normal levels of dioxin. Current opinion is such that options involving the entry of radionuclide contaminated milk into the foodchain, albeit after processing or decontamination would be unacceptable [6]. Similarly, the feeding of contaminated milk to animals would also undermine consumer confidence. Minimising the production of waste milk through drying off would be unacceptable from an animal welfare point of view, and slaughtering would be strongly opposed by the whole of the farming industry. Stakeholders favoured disposal options for milk provided that they followed guidelines to minimise pollution.

\section{RECOMMENDATIONS}

The evaluation of practicability showed that all of the options considered had some limitations to their use. However, these limitations are not of equal importance and are likely to change depending on the specific post accident scenario. It is likely however, that options with high radiological or environmental impacts would be avoided, as would those perceived to undermine consumer confidence. Some options do not operate commercially in the UK and others have legislative restrictions making rapid implementation following an accident difficult. Table 2 highlights those options for which there are serious limitations.

Table 2 Options with serious limitations

\begin{tabular}{|l|l|}
\hline Options & Comments \\
\hline Burning & High environmental impact. \\
Processing/decontamination & Unacceptable to processors, retailers and consumers. \\
Animal feeding & Unacceptable to retailers and consumers. Capacity low. \\
Commercial composting & High radiological impact if radiocaesium present. \\
Biological treatment & High radiological impact if radiocaesium present. Capacity low. \\
Feed additives & Licensing of Prussian blue as a feed additive uncertain after October 2001. \\
Suppress lactation & Synthetic oestrogens illegal. Drying off naturally raises animal welfare concerns. \\
\hline
\end{tabular}

In situ treatments involving the ploughing in and composting of contaminated crops and the landspreading of contaminated milk have the highest practicability. They tend to be the least expensive options and have relatively low environmental and radiological impacts. They are also the options 
preferred by a wide range of stakeholders. In the unlikely situation where contaminated crops have already left the farm, disposal to land fill sites may be considered. Where capacity to landspread milk is limited by the availability of suitable land, disposal of milk via long sea outfalls at STW offers a practicable solution. Reducing or replacing the pasture content of the diet with alternative less or uncontaminated feedstuffs can reduce the volumes of waste milk requiring disposal. Table 3 provides a summary of the recommended options for managing contaminated foodstuffs following a nuclear accident.

Table 3 Recommended options for crops and milk

\begin{tabular}{|l|l|}
\hline Crops & Milk \\
\hline Ploughing in & Landspreading \\
Composting on the farm & $\begin{array}{l}\text { Disposal to sea } \\
\text { Reduce contaminated pasture in diet }\end{array}$ \\
\hline
\end{tabular}

\section{CONCLUSIONS}

(i) In the aftermath of a nuclear accident large volumes of agricultural produce may become contaminated and be considered unfit for human consumption.

(ii) A wide range of options is potentially available to manage contaminated milk and crops either through in situ treatment, diversion to alternative uses or disposal. Options are also available to minimise production of contaminated milk

(iii) Many options have serious limitations with regard to their environmental and radiological impacts. Others undermine consumer confidence.

(iv) In situ treatments are the most practicable. This includes the ploughing in and composting of contaminated crops and the landspreading of milk.

(v) Consideration should be given to disposal of crops to landfill and discharge of milk to sea where capacity for in situ treatment is limited.

(vi) Reducing pasture intake by substitution of alternative, less contaminated diets reduces the volume of contaminated milk produced.

\section{Acknowledgements}

The work was originally funded jointly by the Ministry of Agriculture, Fisheries and Food (MAFF), the Environment Agency (EA) and the National Radiological Protection Board (NRPB). The contribution from MAFF became the responsibility of the Food Standards Agency (FSA) with effect from 1 April 2000. The author is indebted to the NRPB project team comprising Bernard Wilkins, Joanne Brown, Norman Green, Justin Smith, Joanna Marchant, Rona Woodman, Julie Mercer and Sonja Shaw.

\section{References}

[1] CEC. Off. J. Eur. Commu. L211:1-3 (1989).

[2] R.F.M. Woodman, A.F. Nisbet and J.S.S. Penfold, NRPB-R295 (1997)

[3] S. Shaw, N.Green, D.J.B. Hammond and R.F.M. Woodman, NRPB-R328 (2001)

[4] J. Smith, A.F. Nisbet, J.A. Mercer, J. Brown and B.T. Wilkins, NRPB-R330 (2001)

[5] J Brown, B.T. Wilkins and A.F. Nisbet, NRPB-Report (2001, in press)

[6] J.A.Mercer, B.T. Wilkins and A.F. Nisbet, NRPB-Report (2001, in press).

[7] B.T. Wilkins, R.F.M.Woodman, A.F.Nisbet and P.A. Mansfield, NRPB-R323 (2001)

[8] J.K. Marchant, and A.F. Nisbet, NRPB-R329 (2001)

[9] J.K. Marchant, R.F.M. Woodman and A.F. Nisbet, NRPB-Report (2001, in press)

[10] IAEA, IAEA Safety Series No 89 (1998)

[11] NRPB, Docs. NRPB 4:27-41 (1993)

[12] J. Hope, Daily Mail 2 June 2001 